\title{
Falls prevention in community care: 10 years on
}

This article was published in the following Dove Press journal:

Clinical Interventions in Aging

\author{
Elissa Burton' \\ Gill Lewin ${ }^{2}$ \\ Hilary O'Connell ${ }^{3}$ \\ Keith D Hill' \\ 'School of Physiotherapy and Exercise \\ Science, Curtin University, ${ }^{2}$ School of \\ Nursing, Midwifery and Paramedicine, \\ Curtin University, ${ }^{3}$ Independent Living \\ Centre WA, Perth, WA, Australia
}

Correspondence: Elissa Burton School of Physiotherapy and Exercise Science, Curtin University, GPO Box U1987, Perth, WA 6845, Australia

Tel +6I 89266368 I

Fax +6I 892663699

Email e.burton@curtin.edu.au
Background: A million older people living in Australia receive community care services each year due to experiencing functional or mental health difficulties. This group may be at greater risk of falling than similar-aged people not receiving services. However, there is limited falls prevention research for this population.

Purpose: The aim of this study was to identify the falls prevalence rates of older people from 10 Australian community care organizations and compare current falls prevention data to a study 10 years prior that utilized the same 10 organizations. This study also identified factors associated with falling for this population.

Patients and methods: This is a cross-sectional descriptive study, in which 5,338 questionnaires were mailed to a random sample of community care recipients aged $\geq 65$ years.

Results: A total of 1,991 questionnaires were returned (37.3\%), with $47.7 \%$ of respondents having fallen in the previous year, and $32.7 \%$ in the month prior to completing the questionnaire, similar to 10 years prior. Community care clients had a $50 \%$ higher falls rate than that reported for similar-aged people not receiving services, and this remained unchanged over the last 10 years. Eighty-six per cent of fallers had fallen once or twice, and 60\% reported being injured. Thirty-six per cent of respondents reported not being able to get up independently, and only $27.4 \%$ of fallers were referred to a falls prevention program (significantly fewer than 10 years ago; $95 \%$ CI: $0.821-6.366, p=0.01$ ). Balance issues (odds ratio [OR]: $2.06,95 \% \mathrm{CI}$ : $1.288-3.290, p=0.003$ ) and perceived risk of falling in the future being "definite" (OR: 6.42, 95\% CI: 1.890-21.808, $p=0.003$ ) or "unsure" (OR: 3.31, 95\% CI: $1.144-9.544, p=0.027$ ) were risk factors associated with falling. In contrast, individuals referred to a falls prevention intervention had a 47\% reduced likelihood of having fallen ( $95 \%$ CI: $0.281-0.988, p=0.046$ ).

Conclusion: Community care clients should have their falls risk routinely assessed, and at-risk individuals be offered falls prevention advice and referral to fall prevention programs.

Keywords: aging, community care organizations, falls risk, home care, older people

\section{Introduction}

The Australian population aged over 65 years is increasing both in numbers and as a proportion of the population as a whole. ${ }^{1}$ In Australia, people aged $\geq 65$ years who are experiencing functional and/or mental health issues can apply for assistance to stay living in their home through the government-funded aged care program. The community-based care services provided through this program include domestic assistance, personal care, nursing, transport, gardening, and social support. A million older Australians are receiving community aged care services each year. ${ }^{2}$

Experiencing functional difficulties increases a person's risk of falling. ${ }^{3,4}$ Many older people receiving community aged care services will have experienced decreases in strength and balance, bouts of illness, and ongoing pain or injury, which also increase their risk of falling. A study by Smith and Lewin ${ }^{5}$ exploring falls prevalence in a sample of community care clients in Australia a decade ago found $45 \%$ had fallen in 
the previous year. This is $50 \%$ higher than the $30 \%$ prevalence rate, which has been found in studies of the general community-dwelling older population. ${ }^{6,7}$ In contrast, a 2002 study of 2,304 older Canadian home care recipients found only $27 \%$ had fallen in the last year, a rate in line with general older community-dwelling populations. ${ }^{8}$ Other studies investigating falls prevalence among community care clients have only looked at the clients of a single community care organization, ${ }^{9}$ or studied subpopulations, such as people with dementia receiving community care services, ${ }^{10}$ or had shorter data collection periods (30-90 days) limiting the value of comparison of rates between studies. ${ }^{8,11}$

Factors identified as associated with an increased likelihood of future falls among older community care clients have included female gender, having had a previous fall, physical inactivity, balance problems, gait and mobility issues, frailty, and environmental hazards. ${ }^{7,8}$ Similar factors have been found to be associated with increased falls risk in older communitydwelling adults more generally. 3,12

Falls can lead to serious injury such as fractures, head injuries, and even death, ${ }^{13}$ and cost health systems billions of dollars to treat. ${ }^{14,15}$ In the year 2012-2013, almost 100,000 older people were hospitalized due to a fall in Australia. ${ }^{13}$ This accounted for $22 \%$ of all injury-related hospitalized cases. ${ }^{13}$ Being hospitalized as a consequence of a fall increases the probability that an older person will enter residential care, with up to one in five going into residential care directly from hospital. ${ }^{16}$ A specific aim of the community aged care program is the prevention of premature residential care admission. ${ }^{17}$ Yet, despite falls being an obvious contributor to such admissions, there has been no research during the last decade which has examined whether the sector has been successful in reducing the rate of falls (given the substantial growth in successful randomized controlled trials in this period), ${ }^{6}$ and whether other falls data (eg, number of times falling, injuries, referral to falls prevention programs) have improved or remained the same over time. Therefore, the aim of this study is to determine the falls rates of older people receiving services from 10 community care organizations and compare to data from 10 years prior to determine whether improvements have occurred. This study provides community aged care providers with information that will allow them to better target falls prevention strategies or referral.

\section{Patients and methods Study design}

This was a cross-sectional descriptive study in which older people who were receiving services from 10 community care organizations were surveyed by mail. Community care organizations in Australia provide services such as domestic assistance, personal care, nursing, gardening, and social support. These organizations traditionally receive funding from state or federal governments to provide services at home (or in the community) for older people with physical (function) or mental health problems, with the goal to help the older person to stay living independently.

\section{Sample population}

The study population consisted of the 14,113 clients aged $65+$ of 10 community aged care providers in the Perth metropolitan area (Western Australia), at the time of the study. This constituted $20 \%$ of the total Western Australian home and community care population at that time. ${ }^{18}$ All organizations had been involved in a similar prevalence study conducted 10 years earlier, ${ }^{5}$ and depending on their size, sent the study survey to either all of their clients who met the inclusion criteria or to a random sample. The inclusion criteria were receiving community care services from one of the included organizations, living in the community, and aged $\geq 65$ years. Individuals who had a diagnosis of dementia were excluded. After excluding clients meeting this criterion or who did not meet the inclusion criteria, organizations randomly selected clients using the electronic random number generator in excel. The $65+$ age group was chosen because eligibility for home and community care at the time of the study was $\geq 65$ years. A total of 5,338 surveys were sent out in October/November 2015 to $38 \%$ of their older client population.

\section{Survey tool}

The questionnaire was based on that used by Smith and Lewin ${ }^{5}$ in the study 10 years prior; however, a small number of questions were added to address topics not originally examined, such as an older person's ability to rise from the floor independently. The new questionnaire included 45 questions, consisting of a combination of open and closed questions and used the falls definition recommended by the Prevention of Falls Network Europe (ProFaNE) collaboration, "an unexpected event in which the individual comes to rest on the ground, floor, or lower level" (p. 1619), ${ }^{19}$ and it was professionally designed for ease of completion. All questions were self-report, and included sociodemographic data (eg, age, sex, living status), health status, medical or health condition(s), perceived mobility (use of walking aids), and perceived activity levels. Three questions were included regarding vitamin D: does your doctor test you regularly, 
do you have a vitamin D deficiency, and do you take vitamin D supplements daily. Falls data included falls in the last month and year, injuries associated with these falls (allowing injury information for the last three falls), if so type of injuries sustained, medical assistance required for the last three falls, cause of fall, location of fall, and whether assistance was needed to get up from ground after a fall. The survey also asked whether clients had been referred to a falls prevention program in the previous 12 months. The questionnaire was then pilot tested with 13 older clients from three of the participating organizations, and their feedback were used to make some minor modifications before the questionnaire was used in the main study.

\section{Data collection}

A letter explaining the purpose of the study, the questionnaire, and a replied paid envelope were mailed by each provider agency to their selected sample. Consent was assumed by completion and return of the questionnaire.

\section{Data from study 10 years ago}

Eligibility criteria for the Smith and Lewin ${ }^{5}$ study 10 years prior which included the same 10 organizations were similar to the current study: aged $\geq 60$ years, living in the community, and receiving services; those with a diagnosis of dementia were excluded. Sampling was conducted in the same manner as the current study with smaller organizations mailing to all clients meeting the inclusion criteria, while larger organizations randomly sampled their population.

\section{Ethics}

Ethics approval was granted by the Curtin University Human Research Ethics Committee (HREC) and an HREC from one of the community care organizations.

\section{Statistical analysis}

Statistical analyses were performed using Statistical Package for the Social Sciences (SPSS) (version 24). Descriptive statistics were generated for all quantitative data using the complete sample. Data were examined for normality of distribution, and where required, nonparametric tests were used. Comparisons between fallers and non-fallers were undertaken using independent group $t$-tests and chi-square tests. The binary outcome (faller versus non-faller) was used in the univariate and multivariate analyses to identify risk factors associated with falling. Initial univariate analysis involved identifying between-group (faller versus non-faller) differences. Sociodemographic, health conditions and symptoms, mobility and activity levels, medications, and falls prevention data were all included in this analysis, which was not adjusted. A further univariate analysis adjusting for age and sex was then undertaken. Variables with $p \leq 0.1$ in the univariate analysis were included in the multivariate logistic regression analysis, ${ }^{20,21}$ using the hierarchical model. ${ }^{22}$ Covariates that may have potentially correlated were checked using Spearman rank-order correlation, and for those highly correlated $(r>0.7)$, the variable with the highest odds ratio (OR) associated with falling was used. ${ }^{23}$ Potential confounders (eg, age, sex) were adjusted for in the multivariate logistic regression model, and $p$-values $<0.05$ were considered statistically significant.

\section{Results \\ Sociodemographics}

One thousand nine hundred and ninety-one questionnaires were returned, with a response rate of $37.3 \%$. The mean age of the cohort was $81.1 \pm 8.2$ years, and $74.6 \%$ of respondents were female $(n=1,465)$. Seventy-seven per cent lived in a house or unit $(\mathrm{n}=1,438), 17.8 \%$ in an independent living unit in a retirement village $(\mathrm{n}=331)$, and $3.4 \%$ in government housing $(n=64)$. Sixty-four per cent of respondents lived alone $(n=1,164)$; those who did live with someone predominantly lived with their spouse $(71.3 \%, \mathrm{n}=532)$ or a relative $(24.8 \%, n=185)$. Eighty-nine per cent $(n=1,546)$ of respondents indicated they could walk outside their home; however, only $25.1 \%$ reported no trouble walking $(n=469)$. Fifty-seven per cent of respondents were receiving domestic assistance $(n=1,577), 8.3 \%$ social support $(n=228)$, and $6.7 \%$ personal care $(\mathrm{n}=184)$. Ninety-seven per cent of respondents reported taking at least one prescribed medication $(\mathrm{n}=1,799)$ regularly. Table 1 presents a comparison between the fallers and non-fallers for the total sample.

\section{Prevalence of falls}

Forty-eight per cent of respondents reported falling during the previous year ( $\mathrm{n}=949)$, and of these, $32.7 \%$ reported having had a fall $(n=310)$ during the month prior to completing the questionnaire. Of those who reported falling in the previous month, $61.6 \%(n=185)$ had fallen once, $24.5 \%$ twice $(n=76)$, and $13.9 \%$ three or more times $(n=43)$. Of those who had fallen at some time during the previous year, $41.9 \%$ reported falling once ( $n=398), 24.3 \%$ twice $(n=231)$, and $12.3 \%$ thrice $(n=117)$. Fourteen respondents reported falling more than 12 times during the year, with two estimating 60 falls each. These two respondents also reported having balance problems related to their ill-health - one Parkinson's disease and arthritis and the other a stroke, memory loss, and weakness of the legs and back. 
Table I Participant characteristics by falls status

\begin{tabular}{|c|c|c|c|}
\hline Variables & $\begin{array}{l}\text { Fallers } \\
(\mathrm{n}=949)\end{array}$ & $\begin{array}{l}\text { Non-fallers } \\
(n=1,038)\end{array}$ & $p$-value \\
\hline Age (years) & $80.74 \pm 8.57$ & $81.44 \pm 7.94$ & 0.063 \\
\hline \multicolumn{3}{|l|}{ Sex } & 0.361 \\
\hline Male & $247(26.3)$ & $25 I(24.5)$ & \\
\hline Female & $691(73.7)$ & $772(75.5)$ & \\
\hline Lives in home/unit/apartment & $687(72.4)$ & $749(72.2)$ & 0.907 \\
\hline Lives alone & $549(63.0)$ & $614(65.7)$ & 0.229 \\
\hline \multicolumn{3}{|l|}{ Health status } & $<0.001$ \\
\hline Excellent & $31(3.3)$ & $37(3.6)$ & \\
\hline Very good & $156(16.7)$ & $244(23.9)$ & \\
\hline Good & $362(38.7)$ & $426(4 I .7)$ & \\
\hline Fair & $291(31.1)$ & $270(26.4)$ & \\
\hline Poor & $95(10.2)$ & $44(4.3)$ & \\
\hline Ability to walk outside home & $721(85.8)$ & $823(91.9)$ & $<0.001$ \\
\hline \multicolumn{3}{|l|}{ Current perceived mobility } & $<0.001$ \\
\hline No trouble walking & $163(18.1)$ & $306(3 \mid .7)$ & \\
\hline $\begin{array}{l}\text { Some trouble but do not } \\
\text { use aid }\end{array}$ & $222(24.7)$ & $268(27.7)$ & \\
\hline \multicolumn{4}{|l|}{ outside home } \\
\hline Use walking aid outside home & $377(4 \mid .9)$ & $291(30.1)$ & \\
\hline Use walking aid inside home & $67(7.5)$ & $45(4.7)$ & \\
\hline Use wheelchair inside home & $7(0.8)$ & $7(0.7)$ & \\
\hline Other & $5(0.6)$ & $6(0.6)$ & \\
\hline \multicolumn{3}{|l|}{ Current perceived activity level } & 0.003 \\
\hline \multicolumn{4}{|l|}{$30 \mathrm{~min} 3 /$ week } \\
\hline $\begin{array}{l}\text { Moderately active at least } \\
30 \mathrm{~min} 5 / \text { week }\end{array}$ & $215(24.4)$ & $270(28.6)$ & \\
\hline Moderately active at least & $306(34.7)$ & $339(35.9)$ & \\
\hline \multicolumn{4}{|l|}{$30 \mathrm{~min} 2-3 /$ week } \\
\hline \multicolumn{4}{|l|}{ sedentary activities } \\
\hline \multicolumn{4}{|l|}{ Medical conditions or symptoms } \\
\hline Low blood pressure & $150(26.8)$ & $124(20.2)$ & 0.008 \\
\hline Parkinson's disease & $29(5.9)$ & $15(2.7)$ & 0.010 \\
\hline Stroke & $97(19.0)$ & $76(13.1)$ & 0.007 \\
\hline Heart condition & $294(49.1)$ & $294(43.0)$ & 0.030 \\
\hline Dizziness & $244(43.0)$ & $166(27.5)$ & $<0.001$ \\
\hline Memory loss & $162(31.0)$ & $135(22.6)$ & 0.001 \\
\hline Balance problems & $502(72.4)$ & $287(43.8)$ & $<0.001$ \\
\hline Vertigo & $155(29.8)$ & $107(18.9)$ & $<0.001$ \\
\hline Arthritis & $612(80.8)$ & $599(73.7)$ & 0.001 \\
\hline $\begin{array}{l}\text { Weakness of the legs and } \\
\text { back }\end{array}$ & $562(78.7)$ & $495(66.4)$ & $<0.001$ \\
\hline Taking prescribed medications & 871 (97.8) & $927(96.0)$ & 0.028 \\
\hline Vitamin $D$ deficiency & $186(20.5)$ & $173(17.9)$ & 0.010 \\
\hline Problems with vision & $425(47.8)$ & $413(43.8)$ & 0.085 \\
\hline $\begin{array}{l}\text { In hospital the week before } \\
\text { the fall }\end{array}$ & $40(4.3)$ & $6(1.2)$ & 0.002 \\
\hline \multicolumn{3}{|c|}{ Able to get up independently after fall } & $<0.001$ \\
\hline Yes & $519(55.1)$ & $319(60.9)$ & \\
\hline Unsure & $81(8.6)$ & $71(13.5)$ & \\
\hline No & $342(36.3)$ & $134(25.6)$ & \\
\hline Called an ambulance to get up & $121(13.0)$ & $24(3.5)$ & $<0.001$ \\
\hline $\begin{array}{l}\text { Falls prevention referral in last } \\
12 \text { months }\end{array}$ & $248(27.4)$ & $85(10.5)$ & $<0.001$ \\
\hline
\end{tabular}

(Continued)
Table I (Continued)

\begin{tabular}{|c|c|c|c|}
\hline Variables & $\begin{array}{l}\text { Fallers } \\
(n=949)\end{array}$ & $\begin{array}{l}\text { Non-fallers } \\
(n=1,038)\end{array}$ & $p$-value \\
\hline Perceived risk of future falls & & & $<0.001$ \\
\hline Definitely & $205(22.8)$ & $84(9.2)$ & \\
\hline Maybe & $361(40.2)$ & $339(37.3)$ & \\
\hline Unsure & $200(22.2)$ & $203(22.3)$ & \\
\hline Probably not & $117(13.0)$ & $210(23.1)$ & \\
\hline Not at all & $16(1.8)$ & $73(8.0)$ & \\
\hline
\end{tabular}

Of those who reported falling, $27.4 \%$ noted they were referred to a fall prevention program $(n=248)$ during the past year, and $10.5 \%$ of non-fallers reported being referred to a falls prevention program $(\mathrm{n}=85)$.

\section{Injuries and medical assistance from falls}

Sixty per cent ( $\mathrm{n}=566$ ) of the individuals who reported having fallen in the last year $(n=949)$ reported they had sustained an injury. Bruises $(80.4 \%, \mathrm{n}=455)$, cuts and scratches $(41.5 \%$, $\mathrm{n}=235)$, injuries to the head or face $(22.3 \%, \mathrm{n}=126)$, and fractures of any part of the body $(30.6 \%, n=173)$ were the most commonly reported types of injury.

Fifty-eight per cent of respondents who reported being injured did not seek medical assistance $(n=330)$ from a qualified person. Of those who did, $45.0 \%$ said they had seen a doctor in the emergency department or hospital $(n=255)$, $31.8 \%$ saw their local general practitioner (GP) $(n=180)$, and $7.9 \%$ a physiotherapist $(n=45)$.

\section{Location and cause of fall}

Forty-nine per cent of the respondents who had fallen in the previous 12 months had fallen inside their home $(\mathrm{n}=466)$, $25.3 \%$ in their yard $(\mathrm{n}=240)$, and $12.9 \%$ in a public place $(\mathrm{n}=123)$. All other falls were reported as having happened elsewhere. Respondents gave multiple reasons for having fallen - tripped $(25.5 \%, \mathrm{n}=242)$, overbalanced or overreached $(25.3 \%, \mathrm{n}=241)$, and legs giving way $(18.4 \%, \mathrm{n}=175)$ being the most common, followed by not concentrating (16.2\%, $\mathrm{n}=154)$ and rushing $(10.6 \%, \mathrm{n}=101)$.

\section{Rise from floor independently}

Respondents were asked whether they could get themselves up off the ground without assistance. Fifty-seven per cent $(\mathrm{n}=839)$ reported they could, $10.4 \%$ were unsure $(\mathrm{n}=152)$, and $32.4 \%$ said they could not $(\mathrm{n}=476)$. Of the individuals who said they had not been able to get up by themselves after a fall, $16.5 \%$ reported a family member (other than spouse/partner) 
had assisted $(n=102), 22.7 \%$ an ambulance officer $(n=140)$, and $16.5 \%$ spouse or partner $(n=102)$. Others who had assisted included neighbor $(12.3 \%, \mathrm{n}=76)$, friend $(5.7 \%$, $n=35)$, and passerby $(2.4 \%, n=15)$.

\section{Comparison of falls data from study 10 years ago}

Data from the 10 organizations a decade ago reported age in categories with the majority aged $71-80$ years $(35.5 \%)$ and $81-90$ years $(41.6 \%)$, similar to this current study. Other sociodemographic data (eg, sex, living status) were also similar with the proportions in the two studies being within $1 \%-2 \%$ points of each other. There was, however, a substantial difference in response rates, with the response rate in the current study being $37.3 \%$ whereas it was $47 \%$ in the Smith and Lewin study, despite that study mailing out half as many surveys as the current study. Falls data from the Smith and Lewin ${ }^{5}$ study showed an annual falls rate of $44.9 \%$ compared to the rate of this study of $47.7 \%(95 \%$ CI: $-0.244-5.840, p=0.068)$, and a rate of $30.9 \%$ compared to this study's $32.7 \%$ (95\% CI: $-1.043-4.647, p=0.209)$ during the month prior to completing the survey. As in the current study, the majority of community care respondents a decade ago reported falling only once or twice (68\%). Despite the slight increase in falls rate between the two studies, $31 \%$ of respondents in the earlier study reported having been referred to a falls prevention program, whereas this figure was only $27.4 \%$ in the current study. The difference is statistically significant (95\% CI: 0.821-6.366, $p=0.01)$.

\section{Factors influencing falls}

The majority of variables tested in the univariate analyses were found to have a significant association with having fallen (Table 2). The only variables found not to be significant were age, sex, living in a home/unit/apartment, living alone, and problems with vision. The multivariable logistic regression model (Table 2), which included just three variables balance problems, referral to a falls prevention specialist, and subjects' self-perception of falls risk - correctly classified $85 \%$ of faller cases and $69.6 \%$ of overall cases, and was statistically significant $\left(\chi^{2}(17)=74.935, p<0.001\right)$. This model shows that those suffering from balance problems were 2.06 times (95\% CI: 1.288-3.290, $p=0.003$ ) more likely to have fallen than those who did not report balance problems. Those who perceived themselves as "definitely" being at risk of falling in the future were 6.42 times more likely to have fallen ( $95 \%$ CI: $1.890-21.808, p=0.003$ ), compared to those who thought they were at no perceived risk.
Similarly, the odds of having fallen in the past year were 3.31 times greater for those who perceived their risk of future falls as "unsure" (95\% CI: 1.144-9.544, $p=0.027)$ compared to those who perceived no risk at all. Respondents who reported having been referred to a health professional or program to prevent falls in the past year were $47 \%$ less likely (95\% CI: $0.281-0.988, p=0.046)$ to have fallen than those who had not.

\section{Discussion}

This study found the prevalence rate of falls among community care clients to be $47.7 \%$ which was not significantly different from the rate of $45 \%$ found among clients of the same service providers 10 years ago. ${ }^{5}$ This rate is $\sim 50 \%$ higher than that found in studies of community-dwelling older people ( $\sim 30 \%$ fall annually), ${ }^{7}$ not selected on the basis of their use of community care services, as well as Fletcher and Hirdes study of community care clients in which falls data were collected face to face rather than by anonymous questionnaire. ${ }^{8}$ There are frequent anecdotal reports from Australian community care staff and families that older people are reluctant to tell anyone that they have fallen as they are concerned that this may lead to them being admitted to residential care. This may well account, at least in part, for the much lower prevalence rate found by Fletcher and Hirdes. Consistent with this hypothesis, a study in which clients from 22 community care organizations in the Netherlands were interviewed found that just $12.2 \%$ reported having fallen in the previous month, ${ }^{11}$ compared to the $32.7 \%$ found in the present study.

The finding that individuals who reported impaired balance were twice as likely to have fallen is consistent with other studies of both home (community) care clients and older people in general which have also found balance problems to be a major falls risk factor., ${ }^{9,24}$ It is widely reported that participating in an exercise program can reduce falls, and a systematic review by Sherrington et al that examined which types of exercise have been found to be most effective found those challenging balance and including at least 3 hours per week of exercise provided the greatest benefits. ${ }^{25}$ Community care clients are known to have reduced physical activity levels, and many choose walking as their main form of exercise. ${ }^{26,27}$ However, walking is not an exercise that in isolation can reduce falls, ${ }^{28}$ and may even increase falls in at-risk populations if delivered in an unstructured manner. ${ }^{29}$ The high falls rate found in this study, together with the increased risk associated with balance difficulties found in this and other studies, indicate the need for community aged 
Table 2 Analysis of factors influencing falls

\begin{tabular}{|c|c|c|c|c|c|c|c|c|c|}
\hline \multirow[t]{2}{*}{ Variables } & \multicolumn{3}{|c|}{$\begin{array}{l}\text { Univariate analysis } \\
\text { (no adjustments) }\end{array}$} & \multicolumn{3}{|c|}{$\begin{array}{l}\text { Univariate analysis } \\
\text { (adjusted age and sex) }\end{array}$} & \multicolumn{3}{|c|}{$\begin{array}{l}\text { Multivariable analysis } \\
\text { (adjusted age and sex) }\end{array}$} \\
\hline & $\begin{array}{l}\text { Odds } \\
\text { ratio }\end{array}$ & $95 \% \mathrm{Cl}$ & $p$-value & $\begin{array}{l}\text { Odds } \\
\text { ratio }\end{array}$ & $95 \% \mathrm{Cl}$ & $p$-value & $\begin{array}{l}\text { Odds } \\
\text { ratio }\end{array}$ & $95 \% \mathrm{Cl}$ & p-value \\
\hline Age (years) & 0.99 & $0.979-1.00 I$ & 0.063 & & & & 0.98 & $0.957-1.007$ & 0.154 \\
\hline Sex (female/male) & 0.91 & $0.742-1.115$ & 0.361 & 0.99 & $0.98-1.001$ & 0.083 & 0.79 & $0.477-1.290$ & 0.339 \\
\hline Lives in home/unit/apartment (yes/no) & 1.01 & $0.831-1.232$ & 0.907 & 0.99 & $0.811-1.213$ & 0.935 & & & \\
\hline Lives alone (yes/no) & 1.12 & $0.928-1.364$ & 0.229 & 1.08 & $0.882-1.311$ & $0.47 I$ & & & \\
\hline \multicolumn{10}{|l|}{ Health status } \\
\hline Excellent & Referenc & & & & & & & & \\
\hline Very good & 0.76 & $0.455-|.28|$ & 0.306 & 0.78 & $0.467-1.317$ & 0.358 & & & \\
\hline Good & 1.01 & $0.617-1.668$ & 0.956 & 1.02 & $0.618-1.674$ & 0.946 & & & \\
\hline Fair & 1.29 & $0.776-2.132$ & 0.329 & 1.31 & $0.788-2.167$ & 0.3 & & & \\
\hline Poor & 2.58 & $1.420-4.678$ & $0.002 *$ & 2.51 & $1.38-4.565$ & $0.003^{*}$ & & & \\
\hline Ability to walk outside home (yes/no) & 0.54 & $0.395-0.731$ & $\leq\left. 0.00\right|^{\wedge}$ & 0.52 & $0.383-0.712$ & $\leq\left. 0.00\right|^{\wedge}$ & & & \\
\hline \multicolumn{10}{|l|}{ Current perceived mobility } \\
\hline No trouble walking & Referenc & & & & & & & & \\
\hline $\begin{array}{l}\text { Some trouble walking but do not } \\
\text { use aid }\end{array}$ & 1.55 & $1.199-2.017$ & $0.00 I^{*}$ & 1.59 & $1.221-2.067$ & $0.00 I^{*}$ & & & \\
\hline $\begin{array}{l}\text { Need a mobility scooter outside } \\
\text { home }\end{array}$ & 2.53 & $1.634-3.923$ & $\leq 0.00 I^{\wedge}$ & 2.63 & $1.690-4.101$ & $\leq 0.00 I^{\wedge}$ & & & \\
\hline Use walking aid outside home & 2.43 & $1.906-3.104$ & $\leq\left. 0.00\right|^{\wedge}$ & 2.73 & $2.122-3.519$ & $\leq\left. 0.00\right|^{\wedge}$ & & & \\
\hline Use walking aid inside home & 2.79 & $1.831-4.266$ & $\leq\left. 0.00\right|^{\wedge}$ & 3.10 & $2.019-4.754$ & $\leq\left. 0.00\right|^{\wedge}$ & & & \\
\hline Use wheelchair inside home & 1.88 & $0.647-5.444$ & 0.246 & 1.68 & $0.573-4.950$ & 0.344 & & & \\
\hline \multicolumn{10}{|l|}{ Current perceived activity level } \\
\hline Vigorously active $30 \mathrm{~min} 3 /$ week & Referenc & & & & & & & & \\
\hline Moderately active $30 \mathrm{~min}$ 5/week & 1.03 & $0.685-1.533$ & 0.904 & 1.13 & $0.77 \mid-1.665$ & 0.526 & & & \\
\hline Moderately active $30 \mathrm{~min} 3 /$ week & 1.06 & $0.7 \mid 2-1.567$ & 0.784 & 1.29 & $0.886-1.873$ & 0.186 & & & \\
\hline $\begin{array}{l}\text { Seldom active, preferring sendetary } \\
\text { activity }\end{array}$ & 1.27 & $0.846-1.901$ & 0.250 & 1.70 & $1.161-2.480$ & $0.006 *$ & & & \\
\hline $\begin{array}{l}\text { Medical conditions or symptoms } \\
\text { (yes/no) }\end{array}$ & 1.27 & $1.183-1.365$ & $\leq 0.00 I^{\wedge}$ & & & & & & \\
\hline Low blood pressure & 1.45 & $1.102-1.898$ & $0.008 *$ & 1.49 & $1.130-1.958$ & $0.005^{*}$ & & & \\
\hline Parkinson's disease & 2.27 & $1.202-4.284$ & $0.010^{\#}$ & 2.12 & $1.116-4.015$ & $0.022^{\#}$ & & & \\
\hline Stroke & 1.56 & $1.125-2.164$ & $0.007^{*}$ & 1.53 & $1.096-2.124$ & $0.012^{\#}$ & & & \\
\hline Heart condition & 1.28 & $1.023-1.590$ & $0.030^{\#}$ & 1.27 & $1.014-1.585$ & $0.038^{\#}$ & & & \\
\hline Dizziness & 1.99 & $1.557-2.536$ & $\leq\left. 0.00\right|^{\wedge}$ & 1.97 & $1.546-2.52 \mid$ & $\leq\left. 0.00\right|^{\wedge}$ & & & \\
\hline Memory loss & 1.54 & $1.179-2.011$ & $0.001 *$ & 1.57 & $1.195-2.057$ & $0.001 *$ & & & \\
\hline Balance problems & 3.37 & $2.685-4.229$ & $\leq\left. 0.00\right|^{\wedge}$ & 1.22 & $2.648-4.179$ & $0.001 *$ & 2.06 & $1.288-3.290$ & $0.003^{*}$ \\
\hline Vertigo & 1.82 & $1.373-2.4 \mid 4$ & $\leq 0.001^{\wedge}$ & 3.33 & $1.382-2.443$ & $\leq 0.001^{\wedge}$ & & & \\
\hline Arthritis & 1.51 & $1.187-1.915$ & $0.001 *$ & 1.84 & $1.188-1.945$ & $0.001 *$ & & & \\
\hline Weakness of the legs and back & 1.88 & $|.482-2.37|$ & $\leq 0.001^{\wedge}$ & 1.83 & $1.450-2.327$ & $\leq\left. 0.00\right|^{\wedge}$ & & & \\
\hline Taking prescribed medications (yes/no) & 1.83 & $1.060-3.166$ & $0.028^{\#}$ & 1.81 & $1.045-3.145$ & $0.034^{\#}$ & & & \\
\hline Vitamin D deficiency (yes/no) & 1.15 & $1.039-1.272$ & $0.010^{*}$ & 1.16 & $1.050-1.288$ & $0.004^{*}$ & & & \\
\hline Problems with vision (yes/no) & 1.18 & $0.978-1.413$ & 0.085 & 1.19 & $0.990-1.436$ & 0.064 & & & \\
\hline $\begin{array}{l}\text { In hospital the week before the fall } \\
\text { (yes/no) }\end{array}$ & 3.66 & $1.539-8.683$ & $0.002^{*}$ & 3.57 & I.498-8.487 & $0.004^{*}$ & & & \\
\hline $\begin{array}{l}\text { Able to get up independently after fall } \\
\text { (yes/no) }\end{array}$ & 1.22 & $1.085-1.378$ & $0.00 I^{\#}$ & 1.23 & $1.091-1.389$ & $0.001 *$ & & & \\
\hline Called an ambulance to get up (yes/no) & 4.16 & $2.654-6.524$ & $\leq 0.00 I^{\wedge}$ & 4.18 & $2.659-6.564$ & $\leq 0.00 I^{\wedge}$ & & & \\
\hline Falls prevention referral in last & 3.24 & $2.477-4.233$ & $\leq 0.00 I^{\wedge}$ & 3.30 & $2.516-4.339$ & $\leq 0.00 \mathrm{I}^{\wedge}$ & 0.53 & $0.28 I-0.988$ & $0.046^{\#}$ \\
\hline \multicolumn{10}{|l|}{12 months (yes/no) } \\
\hline Perceived risk of future falls & 0.64 & $0.583-0.697$ & $\leq\left. 0.00\right|^{\wedge}$ & 0.64 & $0.580-0.695$ & $\leq\left. 0.00\right|^{\wedge}$ & & & \\
\hline Definitely & & & & & & & 6.42 & $1.890-21.808$ & $0.003^{*}$ \\
\hline Maybe & & & & & & & 2.51 & $0.886-7.080$ & 0.083 \\
\hline Unsure & & & & & & & 3.31 & I.144-9.544 & $0.027^{\#}$ \\
\hline Probably not & & & & & & & 1.80 & $0.627-5.140$ & 0.276 \\
\hline Not at all & & & & & & & Reference & & \\
\hline
\end{tabular}

Notes: ${ }^{*} p<0.05 .{ }^{*} p<0.0$ I. ${ }^{\wedge} p<0.00$ I. 
care organizations to be proactive and actively promote to their clients, or better still provide, exercise programs that include a focus on balance training.

Respondents who considered that they would definitely fall or were unsure whether they might fall were also found in the present study to have a higher likelihood of having fallen in the last year. Increased concern about falling in the future has been found to be associated with getting older in a Canadian study. ${ }^{30}$ An Australian study reported that both over- and underestimation of the risk of falling is common among older people and that these tendencies were highly associated with psychological characteristics, such as anxiety and neurotic personality traits. ${ }^{31}$ A particular concern about the overestimation of falls risks is that it may create a fear of falling which can cause limitation of activities which require mobility. Many studies, including ours, that have found an association of fear of falling with a higher likelihood of having fallen, cannot because of being crosssectional ascertain whether the fear was a result of, or had in fact contributed to, an increased risk of falling through a mediator such as a reduction in physical activity and an increased likelihood of a reduction in their physical capability such as strength and balance. ${ }^{5,8,9}$ Prospective studies such as the very recently reported study by Auais et al have however supported the hypothesis that reduced confidence in the ability to perform activities without falling is associated with an increased likelihood of mobility and physical performance limitations in the future. ${ }^{32}$ Such results indicate a need to find effective interventions to reduce fear of falling. A Cochrane review of exercise intervention trials found a small-to-moderate reduction in fear of falling immediately post-intervention, but the risk of bias was considered high in the majority of studies and a need for higher-quality trials was identified. ${ }^{33}$

There have been many randomized controlled trials demonstrating that a range of single, multiple, and multifactorial interventions can reduce the risk of falling for communitydwelling older people. ${ }^{6}$ These include exercise (with a strength and balance component), tai chi, home safety assessment and modification conducted by occupational therapists for people at high risk of falling, and cataract surgery of the first eye, to be successful in reducing the rate of falls. ${ }^{6}$ Withdrawal of some medications has also resulted in reduced falls risk. ${ }^{6}$ Respondents in the present study who had been referred to a falls prevention program were $47 \%$ less likely to have reported having fallen than individuals who had not been referred. However, only one in five respondents who had fallen had been referred to a falls prevention service/program, and this was significantly fewer than 10 years ago. It is difficult to directly ascribe the cause of this change to one specific factor. However, at least part of this decline in falls prevention referrals may stem from the changes made to the health system in Western Australia during this time period. Previously, there was a community physiotherapy service (CPS) falls prevention program aimed at preventing falls for older community-dwelling people. GPs were able to refer patients directly to this service. However, changes were made and the CPS merged into a general rehabilitation program, and in 2014, GPs were no longer able to directly refer to these services, due to the subacute requirements of activity-based funding in the public system. Referrals could only be accepted from public health service providers (eg, hospitals). CPS also had a number of structural and operational changes which may have also affected their ability to accept services. Data have shown the overall falls rates in Western Australia have risen between 2003 and 2012 (rate: $21.9-27.9$ per 1,000 population) ${ }^{14}$ during this period of change to specific falls prevention programs. Our results indicate the importance of community care organizations referring their clients to a falls prevention service/program as soon as they identify a fall has taken place or when they have identified someone as being at high risk of falling using a validated screening tool. It appears essential for community care organizations to have the ability to refer directly and not have to wait for their clients to be hospitalized, in order to receive falls prevention assistance.

This study has some limitations. First, the response rate for the study was $37 \%$. Bias may therefore have occurred as nonresponders may have shown somewhat different results. While it is possible that individuals who had fallen were more likely to have responded to the survey as they felt it was directly relevant to them, which would have resulted in an overestimation of the fall rate, it is also quite possible that some people who had fallen did not complete the survey as despite assurances that they were anonymous they were concerned about the consequences of admitting they had fallen, and this would have resulted in underestimation. Second, nearly one-fifth of respondents did not answer the questions about their ability to get up after a fall suggesting these results should be treated with some caution. A third limitation is the cross-sectional nature of the study; that is, the information about risk factors was collected at the same time as the falls data making it hard to assess the likelihood of relationships being causal as risk factor profiles may change over time. ${ }^{11}$ Falls data that are collected retrospectively and based on recall have been shown to underestimate falls by 
$\sim 20 \%{ }^{34,35}$ Also, although the current and the 10 years prior survey achieved similar participant profiles on comparison data, many factors may have influenced differences between the two cohorts. Therefore, caution should be used in the interpretation of this comparative data.

The study also had a number of strengths. The study target population can be considered to be representative of the Australian community aged care population as a whole as it included ten agencies that provide a range of services across the Perth metropolitan area which includes socioeconomically and ethnically diverse communities and constituted $20 \%$ of the whole community care population. The use of an anonymous questionnaire allowed people concerned about admitting a fall to family or service provider to admit to having fallen. The study was also designed to minimize the burden on this older population while allowing a large sample size.

\section{Conclusion}

The prevalence rate of falls among community care clients was $48 \%$ which was little different from the rate of $45 \%$ found among clients of the same service providers 10 years ago. ${ }^{5}$ This rate is $\sim 50 \%$ higher than that found in studies of community-dwelling older people not receiving community services. Balance problems and seeing oneself as at high risk of future falls or not being sure about one's risk were associated with a higher likelihood of having fallen, while having been referred to a falls prevention service/program was associated with a reduced likelihood of having fallen. Despite this, only $27 \%$ of fallers had been referred to a falls prevention program. Incorporation of balance exercise programs into their service offerings and early referral to falls prevention programs need to be considered as best practice in Australian organizations providing community aged care services.

\section{Acknowledgments}

This research was funded by a Lotterywest grant (grant number 421004670). The authors would like to thank the Community Care Collaboration Steering Committee and community care clients for their participation in the research.

\section{Disclosure}

The authors report no conflicts of interest in this work.

\section{References}

1. Australian Bureau of Statistics. 3222.0 - Population projections, Australia, 2012 (base) to 2101. 2013. Available from: http://www.abs.gov.au/ ausstats/abs@.nsf/Lookup/3222.0main+features32012\%20(base)\%20 to\%202101. Accessed February 6, 2014.
2. Aged Care Research \& Evaluation Unit. Home and Community Care (HACC) program: minimum data set report 2013-2014. Annual report. Perth, WA: Government of Western Australia, Department of Health; 2014.

3. Ambrose AF, Paul G, Hausdorff JM. Risk factors for falls among older adults: a review of the literature. Maturitas. 2013;75(1):51-61.

4. Gale CR, Cooper C, Aihie Sayer A. Prevalence and risk factors for falls in older men and women: the English Longitudinal Study of Ageing. Age Ageing. 2016;45(6):789-794.

5. Smith J, Lewin G. Home care clients' participation in fall prevention activities. Australas J Ageing. 2008;27(1):38-42.

6. Gillespie LD, Robertson MC, Gillespie WJ, et al. Interventions for preventing falls in older people living in the community. Cochrane Database Syst Rev. 2012;(9):CD007146.

7. Lord SR, Ward JA, Williams P, Anstey KJ. An epidemiological study of falls in older community-dwelling women: the Randwick falls and fractures study. Aust J Public Health. 1993;17(3):240-245.

8. Fletcher PC, Hirdes JP. Risk factors for falling among communitybased seniors using home care services. J Gerontol A Biol Sci Med Sci. 2002;57(8):M504-M510.

9. Isberner F, Ritzel D, Sarvela P, Brown K, Hu P, Newbolds D. Falls of elderly rural home health clients. Home Health Care Serv Q. 1998; 17(2):41-51.

10. Bansal S, Hirdes JP, Maxwell CJ, Papaioannou A, Giangregorio LM. Identifying fallers among home care clients with dementia and Parkinson's disease. Can J Aging. 2016;35(3):319-331.

11. Meijers JM, Halfens RJ, Neyens JC, Luiking YC, Verlaan G, Schols JM. Predicting falls in elderly receiving home care: the role of malnutrition and impaired mobility. J Nutr Health Aging. 2012;16(7):654-658.

12. Deandrea S, Lucenteforte E, Bravi F, Foschi R, La Vecchia C, Negri E. Risk factors for falls in community-dwelling older people: a systematic review and meta-analysis. Epidemiology. 2010;21(5):658-668.

13. AIHW: Pointer S. Trends in hospitalised injury, Australia 1990-00 to 2012-13. Injury research and statistics series no. 95. Cat. no. INJCAT 171. Canberra, ACT: AIHW; 2015.

14. Hendrie D, Miller TR, Randall S, Brameld K, Moorin RE. Incidence and costs of injury in Western Australia 2012. Perth, WA: Department of Health - Chronic Disease Prevention Directorate; 2016.

15. Watson WL, Clapperton AJ, Mitchell RJ. The incidence and cost of falls injury among older people in New South Wales 2006/07. Sydney, NSW: NSW Department of Health; 2010.

16. AIHW: Bradley C. Hospitalisations due to falls by older people, Australia 2009-10. Injury research and statistics series no. 70. Cat. no. INJCAT 146. Canberra, ACT: AIHW; 2013.

17. Australian Government Department of Health and Ageing. Commonwealth HACC Program Manual. Canberra, ACT: Commonwealth of Australia; 2012.

18. Aged Care Research \& Evaluation Unit. Home and Community Care (HACC) program: minimum data set report 2015-2016. Annual report. Perth, WA: Government of Western Australia, Department of Health; 2016.

19. Lamb SE, Jørstad-Stein EC, Hauer K, Becker C; Prevention of Falls Network Europe and Outcome Consensus Group. Development of a common outcome data set for fall injury prevention trials: the Prevention of Falls Network Europe Consensus. J Am Geriatr Soc. 2005;53(9): $1618-1622$.

20. Hosmer DW, Lemeshow S. Applied Survival Analysis: Regression Modeling of Time to Event Data. New York, NY: Wiley; 1999.

21. Hosmer DW, Lemeshow S. Applied Logistic Regression. New York, NY: Wiley; 2000.

22. Munro B. Statistical Methods for Health Care Research. 5th ed. Philadelphia, PA: Lippincott Williams \& Wilkins; 2005.

23. Mukaka MM. Statistics corner: a guide to appropriate use of correlation coefficient in medical research. Malawi Med J. 2012;24(3):69-71.

24. Stolee P, Poss J, Cook RJ, Byrne K, Hirdes JP. Risk factors for hip fracture in older home care clients. J Gerontol A Biol Sci Med Sci. 2009;64(3):403-410. 
25. Sherrington C, Michaleff ZA, Fairhall N, et al. Exercise to prevent falls in older adults: an updated systematic review and meta-analysis. Br J Sports Med. 2017;51(24):1749-1757.

26. Burton E, Lewin G, Boldy D. Physical activity levels of older people receiving a home care service. J Aging Phys Act. 2013;21(2): $140-154$.

27. Burton E, Lewin G, Boldy D. Physical activity preferences of older home care clients. Int J Older People Nurs. 2015;10(3):170-178.

28. Voukelatos A, Merom D, Sherrington C, Rissel C, Cumming RG, Lord SR. The impact of a home-based walking programme on falls in older people: the Easy Steps randomised controlled trial. Age Ageing. 2015;44(3):377-383.

29. Ebrahim S, Thompson PW, Baskaran V, Evans K. Randomized placebocontrolled trial of brisk walking in the prevention of postmenopausal osteoporosis. Age Ageing. 1997;26(4):253-260.

30. Pearson C, St-Arnaud J, Geran L. Understanding Seniors' Risk of Falling and Their Perception of Risk. Ottawa, ON: Statistics Canada; 2014.
31. Delbaere K, Close JC, Brodarty H, Sachdev P, Lord SR. Determinants of disparities between perceived and physiological risk of falling among elderly people: cohort study. BMJ. 2010;341:c4165.

32. Auais M, Alvarado B, Belanger E, Curcio CL, Guralnik JM. Fear of falling predicts incidence of functional limitation two years later. Innov Aging. 2017;1(Suppl 1):925-926.

33. Kumar A, Delbaere K, Zijlstra GA, et al. Exercise for reducing fear of falling in older people living in the community: Cochrane systematic review and meta-analysis. Age Ageing. 2016;45(3):345-352.

34. Fleming J, Matthews FE, Brayne C; the Cambridge City over-75s Cohort (CC75) Study Collaboration. Falls in advanced old age: recalled falls and prospective follow-up of over-90-year-olds in the Cambridge City over-75s Cohort study. BMC Geriatr. 2008;8(6):1-11.

35. Garcia PA, Dias JM, Silva SL, Dias RC. Prospective monitoring and self-report of previous falls among older women at high risk of falls and fractures: a study of comparison and agreement. Braz J Phys Ther. $2015 ; 19(3): 218-226$.
Clinical Interventions in Aging

\section{Publish your work in this journal}

Clinical Interventions in Aging is an international, peer-reviewed journal focusing on evidence-based reports on the value or lack thereof of treatments intended to prevent or delay the onset of maladaptive correlates of aging in human beings. This journal is indexed on PubMed Central, MedLine,

\section{Dovepress}

CAS, Scopus and the Elsevier Bibliographic databases. The manuscript management system is completely online and includes a very quick and fair peer-review system, which is all easy to use. Visit http://www.dovepress. $\mathrm{com} /$ testimonials.php to read real quotes from published authors. 